\title{
Enfermedad Celíaca en Atención Primaria
}

\begin{abstract}
Caso Clínico
Una mujer de 43 años consulta para abrir historia clínica y porque se siente cansada todo el tiempo. Su único antecedente de importancia era padecer una anemia ferropénica en reiteradas oportunidades. El examen físico es normal. En la siguiente consulta trae análisis de laboratorio: $\mathrm{Hb} .6 .5 \mathrm{~g} / \mathrm{dl}$. Hto. $23,3 \%$ reticulocitos $1 \%$, VCM 60 microlitros, plaquetas $447.000 / \mathrm{ml}$, G.B. $3500 / \mathrm{ml}$, ferritina 2.3, colesterol total $110 \mathrm{mg} / \mathrm{dl}$. Resto del laboratorio normal. Se le indica hierro y se realiza una endoscopía digestiva alta para descartar sangrado digestivo, la cual informa esófago y estómago normales y duodeno con severa atrofia vellocitaria que se confirma en la anatomía patológica. Con la sospecha de una posible enfermedad celíaca, solicitó los anticuerpos IgA anti-gliadina (78 UA, normal de 0 a 25), y anticuerpo anti-endomisio (AAE) que dio un resultado positivo.
\end{abstract}

\section{Preguntas que generó el paciente}

1)¿Qué tan frecuente es la presentación de enfermedad celíaca sin el clásico síndrome de malabsorción?

2) ¿Es la anemia ferropénica una forma habitual de presentación de la enfermedad celíaca en atención primaria?

3) ¿Qué porcentaje de las anemias ferropénicas que vemos en la practica clínica son debidas a la enfermedad celíaca y cuándo debo sospecharla?

\section{Búsqueda Bibliográfica}

Medline: pubmed: enfermedad celíaca, anemia ferropénica, epidemiología, diagnóstico.

\section{Resumen de la patología}

La enfermedad celíaca es la auto-agresión inmuno-mediada de la mucosa intestinal que lleva a la manifestación cardinal: la inflamación y atrofia vellocitaria, producida como respuesta a la intolerancia al gluten de la dieta. Su consecuencia es la malabsorción de nutrientes como hierro, ácido fólico, calcio, vitaminas liposolubles. A pesar de que el sindrome de malabsorción clínicamente evidente es la forma de presentación descripta clásicamente, el mismo es mucho menos frecuente de lo que se pensó inicialmente. Desde la mayor disponibilidad de pruebas diagnósticas serológicas, estudios epidemiológicos de diversas partes de mundo muestran una mayor prevalencia de la misma (1 en 200/300 habitantes) con una alta tasa de subdiagnóstico y un claro predominio de las formas oligo-sintomáticas.

En los primeros años de la vida la presentación más frecuente es la forma clásica de malabsorción con diarrea, vómitos, retraso del crecimiento. A medida que los individuos crecen, las formas clínicas se van haciendo menos típicas y en el adulto menos del 50\% de los celíacos tienen síntomas intestinales al momento del diagnóstico.

Del 70 al $90 \%$ de los celíacos tienen anemia y en el $50 \%$ de los casos la anemia es el signo inicial de presentación. La anemia suele ser ferropénica aunque también puede ser mixta por déficit en la absorción de hierro y ácido fólico. Múltiples estudios de cohortes evaluaron la prevalencia de enfermedad celíaca en pacientes con anemia ferropénica. De todos los pacientes con ferropenia, un 5 al $12 \%$ eran celíacos. Este porcentaje fue aún mayor en determinados sub-grupos como los varones, los pacientes con fatiga o perdida de peso, bajo índice de masa corporal, baja albúmina, bajo colesterol en sangre, o aquellos con falta de respuesta al hierro oral. En estos grupos se debería aumentar el índice de sospecha de enfermedad celíaca.
La disponibilidad de las técnicas serológicas ha facilitado el diagnóstico generando un "aparente" aumento de la prevalencia (en realidad un aumento en la detección). Los anticuerpos anti-endomisio y anti-gliadina gozan de excelentes características operativas que los hacen útiles para screening, diagnóstico y seguimiento. Ver tabla:

\begin{tabular}{lllll}
\hline Anticuerpos & Sensibilidad & Especificidad & $\mathrm{CP}+{ }^{*}$ & $\mathrm{CP}-{ }^{*}$ \\
\hline AAE & $95 \%$ & $98-99 \%$ & $47.5-95$ & 0.05 \\
\hline AAG (IG A) & $81 \%$ & $90 \%$ & 8.1 & 0.21 \\
\hline AAG (IG G) & $78 \%$ & $81 \%$ & 4.1 & 0.27 \\
\hline Combinados & $100 \%$ & $95-100 \%$ & 20 -infinito & 0 \\
\hline
\end{tabular}

AAE: anticuerpo anti-endomisio, AAG (IG A) o AAG (IG G): anticuerpo anti gliadina Inmuno Globulina $A \circ G$ respectivamente.

CP+: coeficiente de probabilidad positivo, CP-: coeficiente de probabilidad. *

La confirmación diagnostica debe realizarse con la biopsia de duodeno, que continua siendo el test de referencia o gold standard. Actualmente hay consenso en no realizar las biopsias posteriores (bajo dieta sin gluten y luego del desafio con gluten). La dieta libre de gluten en forma permanente es el tratamiento y la forma de controlar las complicaciones de la enfermedad (osteoporosis, anemia, enfermedades malignas, etc)

\section{Resumen de los trabajos seleccionados}

Coeliac disease in primary care: case finding study. BMJ 1999; 318:164-7.

Objetivo: proveer evidencia del subdiagnóstico de enfermedad celíaca y describir sus principales síntomas de presentación en atención primaria.

Población: Dentro del área de cobertura de un centro de atención primaria que atiende 70.000 habitantes, 1000 personas fueron elegidas para el estudio según los siguientes criterios de inclusión: anemia, historia familiar de enfermedad celíaca, síntomas de malabsorción o diarrea, colon irritable, fatiga, enfermedad tiroidea, diabetes, bajo peso, baja estatura, retraso de crecimiento, epilepsia, infertilidad, artralgia o eccema.

Métodos: búsqueda de casos (case finding) a través de la realización de AAE como método de rastreo a los 1000 pacientes y biopsia de duodeno a los que presentaran AAE positivo.

\section{Lugar: Inglaterra Central.}

Resultados: de los 1000 pacientes, 30 tuvieron AAE positivos y en todos ellos se confirmó el diagnostico de enfermedad celíaca por biopsia. (3\% de la muestra)

De los 30 pacientes celiacos, 25 (el 83\%) no tenían síntomas intestinales y el medico de atención primaria no había sospechado enfermedad celíaca. Los síntomas más frecuentes fueron: anemia (50\%), fatiga (o cansancio) fue el segundo síntoma mas frecuente; y antecedentes familiares, malabsorción o diarrea fueron los siguientes. De los 126 pacientes incluidos por anemia microcítica, 15 fueron celiacos (el 12\%), siendo mayor el porcentaje en varones que en mujeres ( 23 y $11 \%$ respectivamente).

Conclusiones: La presentación más probable en atención primaria fue anemia microcítica, antecedentes familiares y el sentirse cansado todo el tiempo.

Los autores recomiendan la búsqueda de enfermedad celíaca en los pacientes con anemia inexplicable. 
Low plasma colesterol: a correlate of nondiagnosed celiac disease in adults with hypochromic anemia.

Am J Gastroenterol 1999 Jul; 94 (7): 1888-91

Objetivo: Definir la correlación entre enfermedad celíaca y anemia en los adultos sin síntomas de malabsorción.

Población y métodos: 100 pacientes con anemia hipocrómica y sin diarrea fueron sometidos a rastreo con AAE y biopsia de duodeno.

Lugar: Unidad de Gastroenterología de la Universidad de Federico II, Nápoles, Italia

Resultados: 10 pacientes tuvieron diagnostico de enfermedad celíaca ( $10 \%$ de la muestra). En los pacientes con enfermedad celía$\mathrm{ca}$, el colesterol plasmático fue significativamente mas bajo que en el resto $(p<0.001)$. Su valor fue en todos los casos $<156$ $\mathrm{mg} / \%$. La albúmina y el índice de masa corporal fueron menores en los pacientes celíacos, aunque sin alcanzar diferencias estadísticamente significativas.

Conclusiones: La anemia ferropénica es una forma relativamente frecuente de manifestación de la enfermedad celíaca. Un colesterol bajo en sangre debería aumentar el índice de sospecha de la misma en pacientes con anemia hipocrómica.

\section{Comentario final}

* La enfermedad celíaca afecta aproximadamente 1 de cada 250 individuos de la población general

* La aparición de tests serológicos ha facilitado su detección de una manera accesible, sencilla y no invasiva.

* La mayoría de los celiacos vistos en atención primaria se diagnostican en la edad adulta, y los signos de malabsorción suelen estar ausentes.

* La anemia es uno de los síntomas mas frecuente de presentación en las formas oligosintomáticas.

* Ante un paciente con anemia ferropénica los médicos de atención primaria deberíamos considerar a la enfermedad celíaca como diagnostico diferencial especialmente si se constata cansancio o fatiga; colesterol bajo; sexo masculino; antecedentes de varios episodios de anemia o falta de respuesta al hierro; bajo peso o baja albúmina; y ausencia de una causa clara que justifique la anemia.

*Ver glosario

Dra. Verónica Schoj

Unidad de Medicina Familiar y Preventiva. Hospital Italiano de Buenos Aires. 